\title{
Greenhouse, Detached-leaf, and Field Testing Methods to Determine Cucumber Resistance to Gummy Stem Blight
}

\author{
Paul C. St. Amand ${ }^{1}$ and Todd C. Wehner ${ }^{2}$ \\ Department of Horticultural Science, Box 7609, North Carolina State University, Raleigh, \\ NC 27695-7609
}

Additional index words. Cucumis sativus, Cucurbitaceae, Didymella bryoniae, disease resistance, Phoma cucurbitacearum, vegetable breeding

\begin{abstract}
The effects of leaf age, guttation, stomata and hydathode characteristics, and wounding on the symptom development of gummy stem blight [Didymella bryoniae (Auersw.) Rehm] of cucumber (Cucumis sativus L.) were studied to develop a useful germplasm screening method. Older cucumber leaves were more susceptible than younger leaves in field, greenhouse, and detached-leaf tests. Compared to seedlings with true leaves, seedlings at the cotyledon stage were less susceptible, had a smaller variance for ratings, and were more likely to escape infection. Stomata density and hydathode counts were not correlated with field ratings; but, stomata length on older leaves was highly correlated with susceptibility y. In greenhouse and field tests, susceptibility y increased as guttation increased and actively guttating plants were more susceptible than nonguttating plants. Phylloplane moisture and/or nutrition were more important in the infection process than was stomata] opening. Although important, guttation was not necessary for infection. Dawn inoculation of field or greenhouse tests increased leaf symptoms compared with dusk inoculation. The increase was likely due to the free water and nutrients provided by guttation. Genotype ranks and ratings for detached-leaf tests were not correlated with field results. A useful method, highly correlated $(r=0.82$ to 0.96$)$ with field ratings. for screening germplasm in the greenhouse was developed.
\end{abstract}

Methods of artificial inoculation or greenhouse screening of cucumbers (Cucumis sativus) for resistance to gummy stem blight Didymella bryoniae have been reported in at least 15 articles since 1949. Only Wyszogrodzka et al. (1986) indicated that their test was correlated with field resistance. Their report did not specifically measure the correlation between field and greenhouse tests, but found that cultigens (breeding lines, cultivars, and plant introduction accessions) resistant in greenhouse tests were usually resistant in field tests. They stated that the variability in greenhouse tests was problematic, and that greenhouse tests failed to detect the intermediate levels of resistance they found in field tests.

The greenhouse screening method reported by Wyszogrodzka et al. (1986) did not account for the effects of phylloplane nutrition on the infectivity of Didymella bryoniae. Hordijk and Goosen (1962), Svedelius and Unestam (1978), and Svedelius (1990) have demonstrated the importance of nutrition external to the leaf in causing infection by $D$. bryoniae on cucumber. Nutrition external to the leaf stimulates infection by facultative necrotrophs and in some cases is required for infection to occur (Blakeman, 1971). Svedelius (1990) referred to D. bryoniaeas a facultative necrotroph. Curren ( 1969) reported that, like most facultative necrotrophs, $D$. bryortiae produces host cell-degrading enzymes. Svedelius and Unestam (1978) and Svedelius (1990) showed that cucumber leaves were most susceptible to infection near hydathodes, which

Received for publication 19 Sept. 1994. Accepted for publication 14 Feb. 1995. The research reported herein was funded in part by the North Carolina Agricultural Research Service and by a grant from the North Carolina Pickle Producers Association. Use of trade names in this publication does not imply endorsement by the NCARS or the products named, nor criticism of similar ones not mentioned. We gratefully acknowledge the advice of E. Echandi and the technical assistance of R.R. Horton, Jr. The cost of publishing this paper was defrayed in part by the payment of page charges. Under postal regulations, this paper therefore must be hereby marked advertisement solely to indicate this fact.

'Former graduate research assistant. Present address: US DA-ARS, 2004

Throckmorton Hall, Kansas State Univ., Manhattan KS 66506-5501,

${ }^{2}$ Professor; to whom reprint requests should be addressed. exude carbohydrates, salts, and minerals (Ivanoff, 1963). Svedelius and Unestam (1978) speculated that guttation may provide $D$. bryoniae with increased infectivity. Yarwood (1952) found that infection of broad bean (Vicia faba L.) inoculated with Botrytis cinerea was positively correlated with the amount of guttation. The effects of leaf exudates on the field resistance of cucumbers to D. bryoniae has not been investigated.

There are conflicting reports on the infectability of cucumber cotyledons and on the relative susceptibility of differently aged leaves. Chiu and Walker (1949), Van Der Meer et al. (1978), and Wyszogrodzka et al. (1986) found that cotyledons of cucumber at the seedling stage were resistant to D. bryoniae and that inoculation of cotyledons was unreliable. Lee et al. (1984), however, stated that cucumber cotyledons were regularly infected in their tests, but it is unclear whether the plants tested were at the cotyledon stage or were 1 month old. Van Steekelenburg (1985) concluded that wounding was essential for infection of older leaves but not for young leaves. However, that conclusion was based on tests in which old leaves were not inoculated in the same manner as young leaves. Also, in an earlier paper, Van Steekelenburg (198 1) showed that the relative susceptibility of old vs. young leaves depended on the cultigen used. Contrary to Van Steekelenburg's work, Hordijk and Goosen (1962) found that old leaves were more susceptible to D. bryoniae, and Van Der Meer et al. (1978) showed that the meristem and primordial true leaves were less susceptible than the first true leaf. Also, Prasad and Norton (1967) stated that cucumber leaves become more susceptible to $D$. bryoniae with age.

Detached-leaf tests that detect field resistance to plant pathogens in a number of crops have been developed (Deadman and Cooke, 1986; Randhawa and Civerolo, 1985; Tedford et al., 1990; Yarwood, 1946;). Detached-leaf tests have a number of advantages over other methods such as multi-race or multi-pathogen testing without complications from systemic acquired resistance, the ability to test and maintain susceptible plants (which is impor- 
tant in genetic testing), and increased replication (by using more leaves) when testing single plants of unique genotypes. Hordijk and Goosen ( 1962) briefly mention that detached leaves of cucumber were susceptible to D. bryoniae.

Host penetration of $D$. bryoniae on cucumber usually occurs through intercellular spaces around abraded trichomes (Chiu and Walker, 1949) or intercellularly via the stigma or style (de Neergaard, 1989). Direct cell penetration has not been noted (Chiu, 1948) or occurs only rarely (Chiu and Walker, 1949). Stomatal entry of $D$. bryoniae occurred on watermelon [Citrullus lanatus (Thunb.) Matsum. \& Nakai] rind (Schenck, 1962), and cucumber leaves were most susceptible to infection near hydathodes (Svedelius, 1990; Svedelius and Unestam, 1978), indicating that a possible link may exist between stomata or hydathode characteristics and susceptibility.

Our objectives for this study were to 1) determine the effects of leaf age, guttation, stomata and hydathode characteristics, and wounding on the correlation between field and greenhouse tests and between field and detached-leaf tests for resistance to $D$. bryoniae on cucumber; 2) develop a useful method for screening cucumbers in the greenhouse for resistance to D. bryoniae, and 3 ) investigate the importance of guttation, irrigation, plant size, and wounding on the field resistance of cucumbers to D. bryoniae.

\section{Materials and Methods}

Inoculum preparation. For all tests, one pathogenic single spore isolate of $D$. bryoniae (DB-H-23, collected by Charles Averre from diseased cucumber leaves in 1988 in Duplin county, N. C.) was increased on petri plates containing $10 \mathrm{ml}$ of cucumber malt extract agar (CMEA), using mycelial plug inoculation. Each liter of CMEA was made by mixing $250 \mathrm{ml}$ of cucumber purée and $750 \mathrm{ml}$ of distilled water with $30 \mathrm{~g}$ of malt extract agar (Difco). The purée, made from whole, freshly harvested cucumbers, was autoclave on 2 consecutive days and then stored at 0C until needed. Inoculated plates were incubated for 10 to 14 days at $24 \pm 2 \mathrm{C}$ under alternating periods of $12 \mathrm{~h}$ fluorescent light [40 to 90 $\mu \mathrm{mol} \cdot \mathrm{m}^{-2} \cdot \mathrm{s}^{-1}$ photosynthetic photon flux density (PPFD)] and $12 \mathrm{~h}$ darkness until spore-producing pycnidia formed. Inoculum was prepared by flooding plates with 5 to $10 \mathrm{ml}$ of acidified, steriledistilled water and scraping the surface of the agar with a rubber spatula. The water was acidified to a $\mathrm{pH}$ of 3.5 to 4.5 using lactic acid and also contained 20 drops/liter Tween-80, a surfactant. The low $\mathrm{pH}$ and the surfactant increased spore discharge from pycnidia and greatly reduced spore agglutination. The liquid from each plate was filtered through four layers of cheesecloth to remove mycelia, pycnidia, and dislodged agar. The spore suspension was standardized to a concentration of $\approx 1 \times 10^{6}$ spores $/ \mathrm{ml}$ using a hemacytometer. The final $\mathrm{pH}$ of the inoculum was unadjusted and ranged from 5.4 to 6.8 . The inoculum was held at $5 \mathrm{C}$ for $\approx 15 \mathrm{~h}$ until use. Immediately before inoculation, Tween-80 (10 drops/liter), case in hydrolysate $(0.05 \% \mathrm{w} / \mathrm{v}$, Sigma), and sucrose or dextrose $(0.1 \% \mathrm{w} / \mathrm{v}$, Sigma $)$ were added to the inoculum, except where noted. Plant symptoms were enhanced equally well with casein hydrolysate combined with either sucrose or dextrose (data not shown).

Rating scale and variables measured. In all tests and for all measures of disease symptoms, a linear 0 to 9 scale was used. Each increment of the scale is about equivalent to an $11 \%$ increase in symptom area. A rating of 0 indicated no visible symptoms. A rating of 9 indicated maximum symptoms. As an initial guide to leaf area damage, ratings from 1 to 8 were based on the pictorial assessment key of Thompson and Jenkins (1985). Detached leaves were rated for chlorosis and pycnidia formation. Ratings were made on individual leaves and chlorosis and pycnidia formation were rated separately. A chlorosis rating of 9 indicated that the entire leaf was uniformly and intensely chlorotic. Pycnidia formed almost entirely on leaf margins. A pycnidia rating of 9 indicated that the entire leaf margin was uniformly and densely covered with pycnidia. In field tests, plots were rated for leaf and stem necrosis. A leaf rating of 9 indicated that all leaves on all plants in a plot were entirely and uniformly necrotic. Stems were rated only on the lower $30 \mathrm{~cm}$ of main stems. A stem rating of 9 indicated that the main stems of all plants in a plot were entirely necrotic. Ratings of 9 for leaves or stems were rarely noted. Plants inoculated at the cotyledon stage were rated 9 if both cotyledons were completely necrotic. Plants inoculated at the first true leaf stage were rated 9 if the first true leaf was completely necrotic. A rating of 9 was assigned if the first and second true leaves were completely necrotic in plants inoculated at the third true leaf stage.

The rating scale data were checked for violations of the assumptions required for the analysis of variance using residual plot analysis as suggested by Fernandez (1992). Residuals were randomly distributed in all experiments; therefore, transformation of the rating scale data was not necessary (Little, 1985).

For all experiments, analysis of variance was performed using PROC GLM (SAS Institute, 1988). Means were tested for significant differences using the LSD option of the means statement in PROC GLM. Preplanned comparisons of specific treatment combinations were tested using single degree of freedom contrasts. Pearson product-moment correlation and Spearman rank correlation coefficients were calculated using PROC CORR (SAS), for the variables measured in this study with the field ratings reported by Wehner and St. Amand ( 1993).

Greenhouse methods. Seeds of each cultigen were planted in standard, $100-\mathrm{mm}(500-\mathrm{ml})$ round, plastic pots filled with a soilless mix of peat, vermiculite, and perlite (Metro Mix 220, GraceSierra, Milpitas, Calif.) in greenhouses at Raleigh, N.C. Where indicated, a soluble complete fertilizer (Peters 20-20-20; GraceSierra), was applied as a soil drench 1 and 2 weeks after seeding at a rate of $10 \mathrm{~g} /$ liter of water. Except for detached-leaf tests and field tests, inoculum was sprayed on the entire plant as a very fine mist using an air brush (model 100; Badger Air Brush Co., Franklin Park, Ill.) at $\approx 140 \mathrm{kpa}(20 \mathrm{psi})$ and at a distance of $\approx 20 \mathrm{~cm}$. Plants were sprayed nearly to the point of runoff, allowing guttation fluids to remain.

Table 1. Mean rating of foliar necrosis caused by Didymella bryoniae on 10 cucumber cultigens field tested in 4 years and 2 locations (Wehner and St. Amand, 1993).

\begin{tabular}{lc}
\hline \hline Cultigen & Mean foliar rating \\
\hline PI 164433 & 1.8 \\
Slice & 2.9 \\
NCSU M 17 & 3.2 \\
PI 200818 & 4.2 \\
Poinsett 76 & 4.2 \\
Wisconsin SMR 18 & 5.7 \\
Straight 8 & 5.8 \\
Marketmore 76 & 6.6 \\
PI 205995 & 8.0 \\
Colet & 8.1
\end{tabular}

${ }^{2}$ Means were used in calculations of phenotypic and rank correlations between field resistance and the detached-leaf and greenhouse tests described in this study. Rating scale was from 0 (no necrosis) to 9 (complete necrosis) in $11 \%$ increments of necrotic area. 
Immediately after inoculation, plants were placed into a chamber maintained at $95 \%$ to $100 \%$ relative humidity $(\mathrm{RH})$ and 22 to $26 \mathrm{C}$ with no light for $48 \mathrm{~h}$. The chamber doors were removed after $48 \mathrm{~h}$ and the plants remained in the open chamber for an additional $24 \mathrm{~h}$, allowing the plants to gradually re-acclimate to the ambient greenhouse environment. Before and after inoculation, plants in all treatments were watered daily with equal amounts of water using overhead sprinklers.

Field data for correlations. Field data from Wehner and St. Amand (1993) were used in calculations of correlations between field resistance and the detached-leaf and greenhouse tests described in this. study. Means from that study span 4 years and two locations and provide the best information available on the field resistance of resistant and susceptible cucumber cultigens. Leaf susceptibility in their study was rated from 0 to 9 , as described above for the field test in this study. Cultigens used in the experiments below are listed in Table 1 along with their mean leaf rating for field resistance to $D$. bryorziae as reported by Wehner and St. Amand (1993).

\section{Detached-leaf test}

Plant material and treatments. The effect of leaf age on resistance and on the correlation between a detached-leaf test and field resistance was tested using six cultigens ranging from resistant to susceptible. Cultigens used, in order from most field resistant, were 'Slice', NCSU M 17, PI 200818, 'Wisconsin SMR 18', 'Straight 8', and 'Marketmore 76'.

Greenhouse temperature ranged from 25 to $35 \mathrm{C}$ and $\mathrm{RH}$ ranged from 55\% to 95\%. Beginning on 4 Feb. 1992 for Expt. 1 and on 9 Apr. 1992 for Expt. 2, five pots were seeded for each cultigen every 3 days for four planting dates to ensure that all plants were at the same developmental stage when testing began, regardless of germination and growth rates. Plants in this study were fertilized. For each cultigen, three plants at the fourth true leaf stage were chosen for use in the study. Plants were selected if the fourth true leaf had a width of $6 \pm 1 \mathrm{~cm}$. All four leaves of each plant were removed by cutting the petioles from the stem. Leaves were collected at dusk when nutrient and carbohydrate levels are highest (Yarwood, 1946). Leaves were rinsed in distilled water and cut latitudinally to forma triangular leaf piece, which, including the leaf tip, was $6 \pm 1 \mathrm{~cm}$ long.

Leaf pieces were inoculated by submerging for $\approx 2 \mathrm{sec}$ in inoculum prepared as above, except that casein hydrolysate and sucrose were not added. Adding nutrients to the inoculum for leaf pieces promoted profuse secondary pathogen growth. Noninoculated controls were submerged in distilled water with Tween-80 (10 drops/ liter). Leaf pieces were floated, adaxial side up, on $10 \mathrm{ml}$ of sterile distilled water in $100 \times 15-\mathrm{mm}$ plastic sterile petri plates (Fisher Scientific, Pittsburgh). Plates were sealed with two layers of parafilm
M (American National Can, Greenwich, Corm.) and incubated in $12 \mathrm{~h}$ light at 40 to $90 \mu \mathrm{EM} \cdot \cdot^{-2} \cdot \mathrm{s}^{-1}$ of PPFD and $12 \mathrm{~h}$ dark at $24 \pm 2 \mathrm{C}$.

Experimental design. The effects of cultigen and leaf age on final chlorosis and pycnidia ratings (rating on day 10 after inoculation) and on the area under the disease progress curve (AUDPC) for chlorosis and pycnidia ratings were tested using a randomized complete-block design with three. replications. The experiment was run twice. Chlorosis and pycnidia formation were rated as described above every 2 days up to 10 days after inoculation. The AUDPC was calculated for chlorosis and pycnidia formation for each leaf using the method described by Campbell and Madden (1990).

\section{Guttation and resistance}

Plant material and treatments. The effects of kinetin, 2,4dichlorophenoxyacetic acid (2,4-D, a synthetic auxin), and time of inoculation on resistance and on the con-elation with field resistance were tested using five cultigens ranging from resistant to susceptible. Cultigens used, in order from most field resistant, were 'Slice', 'Poinsett 76', 'Straight 8', 'Marketmore 76', and 'Colet'.

Greenhouse temperature ranged from 25 to $35 \mathrm{C}$ and the $\mathrm{RH}$ ranged from $45 \%$ to $95 \%$. Plants in this study were fertilized. Plants were selected if the third true leaf had a width of $6 \pm 1 \mathrm{~cm}$. Plants were sprayed to runoff $24 \mathrm{~h}$ before inoculation with 2,4-D (10 mg.liter ${ }^{-1}$, dissolved in 5 drops ethanol), kinetin (10 mg.liter ${ }^{-1}$, dissolved in 5 drops $\mathrm{NaOH}$ ), or distilled water. Growth regulator and water sprays also contained Tween-80 ( 10 drops/liter). Inoculum without casein hydrolysate or sucrose was prepared as described above. Plants were inoculated at dawn or dusk on 22 Oct. 1992 for Expt. 1 and on 25 Nov. 1992 for Expt. 2. Three plants of each cultigen were sprayed with growth regulators but were left uninoculated to observe the effects of growth regulators alone. Plants were inoculated, incubated, and rated as described above.

Experimental design. The effects of growth regulators and time of inoculation on foliar resistance were tested using a split-plot design with four replications. Whole plots were time of inoculation, and subplots were growth regulator treatments. Cultigens were randomized within subplots. The experiment was run twice. Necrosis was rated, as above, 10 days after inoculation.

\section{Stomata, hydathodes, and resistance}

Plant material and treatments. The effects of stomata density (number of stomata $\times \mathrm{mm}^{-2}$ ), stomata length, and hydathode number (number/cm of leaf margin) on resistance and on the correlation with field resistance were tested using six cultigens ranging from resistant to susceptible. Cultigens used, in order from most resistant, were PI 164433, 'Slice', NCSU M 17, 'Wisconsin SMR 18', 'Marketmore 76', and PI 205995.

Greenhouse temperature ranged from 20 to $38 \mathrm{C}$ and the $\mathrm{RH}$

Table 2. Contrast mean squares for the area under the disease progress curve (AUDPC) and final rating (rating on day 10) for chlorosis and pycnidia ratings of cucumber leaves inoculated with Didymella bryoniae. The first four true leaves from six cultigens differing for resistance to D. bryoniae were tested as detached leaves in petri plates. Ratings were measured every other day for 10 days and ranged from no symptoms (0) to complete chlorosis (9) or to leaf margins completely covered with pycnidia (9). The experiment had three replications and was performed twice.

\begin{tabular}{lcrrrr}
\hline & & \multicolumn{2}{c}{ Chlorosis } & & \multicolumn{2}{c}{ Pycnidia } \\
\cline { 3 - 6 } Contrasts & $\mathrm{df}^{*}$ & AUDPC & Final rating & AUDPC & Final rating \\
\hline Leaf 1 vs. leaf 2 & 1 & $4.34^{\mathrm{NS}}$ & $2.25^{\mathrm{NS}}$ & $5.33^{\mathrm{NS}}$ & $2.73^{\mathrm{NS}}$ \\
Leaf 2 vs. leaf 3 & 1 & $297.02^{*}$ & $1.17^{\mathrm{NS}}$ & $1133.71^{* * *}$ & $51.80^{* * *}$ \\
Leaf 3 vs. leaf 4 & 1 & $836.94^{* *}$ & $156.50^{* * *}$ & $345.14^{* * *}$ & $58.09^{* * *}$ \\
\hline
\end{tabular}

$\overline{\mathrm{Ns}}, *, * *, * * *$ Nonsignificant or significant at $P=0.05,0.01$, or 0.001 , respectively. 
ranged from $55 \%$ to $95 \%$. Plants were fertilized as described above. Plants were selected if the third true leaf had a width of $6 \pm$ $1 \mathrm{~cm}$. The first, second, and third true leaf of each plant was removed and examined for stomata density, stomata length, and hydathode number. Stomata density was measured by direct counts on fresh leaves at a magnification of $80 \times$. Stomata length was measured using an ocular micrometer at a magnification of $360 \times$. Hydathocles were counted without magnification by counting the number of primary, secondary, and tertiary vein endings per centimeter of leaf margin in the most deeply lobed region of each leaf.

Experimental design. For stomata density and length, three plants of each cultigen were examined. The adaxial and abaxial surfaces of the first three true leaves were examined at two locations. The center location was within $1 \mathrm{~cm}$ of the leaf midrib in the center of the leaf and in the center of an areole. The edge location was within $5 \mathrm{~mm}$ of the leaf margin and within $1 \mathrm{~cm}$ of the most deeply lobed portion of the leaf and in the center of an areole. Two samples were taken at each location. For hydathode counts, three plants of each cultigen were examined. The first three true leaves were examined on each leaf half. A completely nested design was used.

\section{Greenhouse methods}

Plant material and treatments. The effects of time of inoculation, leaf age, and wound status on the resistance of greenhouse grown plants and on the correlation with field resistance were tested using six cultigens ranging from resistant to susceptible. Cultigens used, in order from most field resistant, were 'Slice', PI 200818, NCSU M 17, 'Wisconsin SMR 18', 'Straight 8', and PI 205995.

Greenhouse temperature ranged from 27 to $39 \mathrm{C}$ and the $\mathrm{RH}$ ranged from $65 \%$ to $100 \%$. Pots were seeded for each cultigen every 3 days for 12 planting dates to ensure the availability of plants at three developmental stages when testing began, regardless of germination and growth rates. Fertilization was as described above. Plants were selected at the cotyledon stage (fully expanded cotyledons and first primordial leaf $<1 \mathrm{~cm}$ long), at the first true leaf stage (first true leaf fully expanded and second true leaf $<3 \mathrm{~cm}$ wide), and at the third true leaf stage (third true leaf 6 $\pm 1 \mathrm{~cm}$ wide and fourth true leaf $<3 \mathrm{~cm}$ wide). Wounding was performed by dusting leaves with Carborundum (320 grit) and rubbing the dusted area lightly with a cotton ball. Inoculum with casein hydrolysate and sugar was prepared as above. Plants were inoculated at dawn or dusk on 22 June 1992 for Expt. 1 and on 23 Sept. 1992 for Expt. 2. Plants were inoculated, incubated, and rated as described above.

Experimental design. The effects of time of inoculation, leaf age, and wounding on foliar resistance were tested using a splitsplit-plot design with four replications. Whole plots were time of inoculation, subplots were plant size treatments, and sub-subplots were wounding treatments. Cultigens were randomized within sub-subplots. The experiment was run twice. Leaf necrosis was rated, as above, 10 to 14 days after inoculation.

\section{Field methods}

Plant material and treatments. The effects of irrigation, plant size, wound status, and time of inoculation on leaf and stem resistance were tested in five field environments using three cultivars ranging from resistant to susceptible. Cultivars used, in order from most field resistant, were 'Slice', 'Dasher II', and 'Straight 8'.

Plants were grown in five environments as follows: 1) Castle Hayne, N. C., in Spring 1991, 2) Castle Hayne in Summer 1991, 3) Castle Hayne in Spring 1992,4) Castle Hayne in Summer 1992, and 5) Clayton, N.C., in Summer 1992. For the period between inoculation and rating, total precipitation and average temperature at each environment were as follows: environment $1,0 \mathrm{~mm}$ and $26 \mathrm{C}$; environment $2,1.3 \mathrm{~mm}$ and $27 \mathrm{C}$; environment $3,3.8 \mathrm{~mm}$ and $23 \mathrm{C}$; environment $4,0 \mathrm{~mm}$ and $28 \mathrm{C}$; and environment $5,0 \mathrm{~mm}$ and 24C. Seasons may be considered as environments because they have been shown to contribute greatly to environmental variation for yield in cucumber (Wehner, 1987) and disease reactions vary greatly between seasons (Wehner and Horton, 1992). Standard cultural practices were used in each environment (Hughes et al., 1983). Irrigation treatments consisted of applying 15 to $30 \mathrm{~mm}$ of water per hectare by overhead sprinklers either zero, one, or three times per week postinoculation for 2 weeks. Duration of leaf wetness was not recorded. No method was used to prevent irrigation by rain. Before inoculation and within each environment, all treatments received the same amount of irrigation, and all treatments were irrigated at the above rate 10 to $16 \mathrm{~h}$ before inoculation. There were two planting dates at each environment, differing by 4 to 6 weeks, which by the time of inoculation provided plants either smaller or larger than the vine-tip-over stage (four to six true leaves). Plants were wounded 1 to $7 \mathrm{~h}$ before inoculation or left unwounded. Wounding was applied by swinging a $10 \times 40-\mathrm{cm}$ wooden plank three times through the plant canopy of each plot at a rate of $\approx 2 \mathrm{~m} \cdot \mathrm{s}^{-1}$. Wounding injured leaves and stems in a manner similar to that of multiple hand harvesting. Plants were inoculated at dawn or dusk. Inoculum with casein hydrolysate and sucrose was prepared as above. Inoculum was sprayed on leaves and stems as a very fine mist using a Solo backpack sprayer at 140 to $200 \mathrm{kP}$ (20 to 30 psi). Plants were sprayed nearly to the point of runoff, allowing guttation fluids to remain.

Experimental design. The effects of irrigation, plant size, wound status, and time of inoculation on leaf and stem field resistance were tested using a split-plot design with three replications. Whole plots were irrigation treatments, subplots were randomly assigned

Table 3. Contrast mean squares for leaf rating of cucumber leaves inoculated with Didymella bryoniae. Cultigens differing for resistance to $D$. bryoniae were tested in a greenhouse at the third true leaf stage. Time of inoculation was at dawn or dusk. Growth regulator treatments were kinetin, 2,4-D, or none. Ratings were measured 10 days after inoculation and ranged from no symptoms (0) to complete necrosis (9) in 1170 increments of necrotic area. The experiment had four replications and was performed twice.

\begin{tabular}{lcc}
\hline \hline Contrasts & df & Mean square \\
\hline Dawn-inoculated vs. dusk-inoculated & 1 & $350.4^{* * *}$ \\
Kinetin vs. no growth regulator & 1 & $57.6^{* * *}$ \\
No growth regulator vs. 2,4-D & 1 & $102.4^{* * *}$ \\
Dawn, no growth regulator vs. dusk, 2,4-D & 1 & $12.8^{\text {Ns }}$ \\
Dawn, kinetin vs. dusk, 2,4-D & 1 & $16.2^{*}$
\end{tabular}

Ns $, *, * *, * * *$ Nonsignificant or significant at $P=0.05$ or 0.001 , respectively. 
treatment combinations of plant size, wound status, time of inoculation, and cultivar. The experiment was run in five environments. Plots were rated for leaf and stem necrosis as above 10 to 14 days after inoculation. An index rating was calculated as the average of leaf and stem ratings.

\section{Results}

Detached leaf test. Ratings on day 10 after inoculation or for the AUDPC for chlorosis $(P \leq 0.01)$ and pycnidia $(P \leq 0.05)$ formation were significantly different among cultigens in the detached-leaf test. However, ratings were not correlated with the field ratings shown in Table 1, as indicated by nonsignificant correlations ranging from -0.56 to 0.08 for all variables.

Susceptibility increased with leaf age for all cultigens tested for chlorosis and pycnidia formation (data not shown). Averaged over cultigens, all ratings on the oldest leaf (leaf 1 ) were 2.5 to 3.7 times greater than that of the mean rating for the youngest leaf (leaf 4). Single degree of freedom contrasts indicate that ratings were significantly different between the two youngest leaves (leaf 3 and leaf 4) for all variables (Table 2). The same was true for leaves 2 and 3 except for the final chlorosis rating. There were no differences between the two oldest leaves for any variable. Even though the greatest source of variation was due to experiments, interactions involving experiments were either nonsignificant or had no change in treatment ranks, indicating that results were consistent between experiments.

Guttation and resistance. Greenhouse grown plants inoculated at dawn were guttating heavily and those inoculated at dusk had no visible signs of guttation. The effect of time of inoculation was highly significant $(P \leq 0.001)$. Dawn inoculated plants were more susceptible than dusk inoculated plants. The mean leaf rating was 6.6 for plants inoculated at dawn and 4.7 for plants inoculated at dusk.

In this study, 2,4-D visibly increased guttation slightly, and kinetin visibly decreased guttation slightly compared to plants receiving no growth regulator treatment. However, the amount of guttation was not measured. Growth regulators significantly affected the leaf rating of plants inoculated with $D$. bryoniae as indicated by contrasts (Table 3 ). The mean leaf rating of plants treated with 2,4-D was 6.9. Those plants receiving no growth regulator had a mean leaf rating of 5.3, and plants treated with kinetin had a mean leaf rating of 4.1 .

Time of inoculation interacted significantly with growth regulator treatments, but changes in the ranking of treatment combinations did not occur. The mean leaf rating of plants treated with no growth regulator and inoculated at dawn was not significantly different from that of plants treated with 2,4-D and inoculated at dusk (Table 3). The mean leaf rating (5.3) of plants treated with kinetin and inoculated at dawn was significantly lower than (6.2) that of plants treated with 2,4-D and inoculated at dusk (Table 3). Uninoculated control plants sprayed with growth regulators had no necrotic lesions.

Leaf rating was significantly different among cultigens $(P \leq$ 0.001). Correlations between greenhouse leaf ratings and the field leaf ratings in Table 1 were calculated for each of the six combinations of time of inoculation by growth regulator treatment. Averaged over experiments, mean leaf ratings for cultigens treated with no growth regulator and inoculated at dawn were highly correlated $(r=0.92, P \leq 0.05)$ with field ratings, as were rankings $(r=0.90, P \leq 0.05)$. Rankings for cultigens treated with $2,4-\mathrm{D}$ and inoculated at dusk were highly correlated $(r=0.82, P \leq 0.05)$ with field rankings, but the mean leaf ratings were not significantly correlated $(r=0.86, P \geq 0.05)$ with field ratings. Cultigens treated with 2,4-D and inoculated at dawn had mean leaf ratings that were highly, but nonsignificantly, correlated $(r=0.83, P \geq 0.05)$ with field ratings, as were rankings $(r=0.82, P \geq 0.05)$. All other treatment combinations had low and nonsignificant correlations with field ratings.

Stomata, hydathodes, and resistance. Cultigens $(P \leq 0.001)$ and

Table 4. Contrast mean squares for stomata density per square millimeter, stomata length in millimeters, and hydathode count per centimeter leaf margin in a completely nested design for six cucumber cultigens grown in a greenhouse. Stomata counts and length were sampled twice at two locations (leaf center and margin), nested in leaf surface (top or bottom), nested in leaf (first, second, or third true leaf), and nested in plants of each cultigen. Hydathode counts were sampled twice at the leaf margin in the most deeply lobed section of leaves.

\begin{tabular}{|c|c|c|c|c|}
\hline Contrasts & $\begin{array}{c}\text { Stomata } \\
\text { df }\end{array}$ & $\begin{array}{c}\text { Stomata } \\
\text { density }\end{array}$ & $\begin{array}{l}\text { Hydathode } \\
\text { length }\end{array}$ & count \\
\hline Leaf 1 vs. leaf 2, averaged over cultigens & 1 & $101,250^{\mathrm{NS}}$ & $4.5^{\mathrm{NS}}$ & $2.0^{\mathrm{NS}}$ \\
\hline Leaf 2 vs. leaf 3 , averaged over cultigens & 1 & $690,312^{\mathrm{Ns}}$ & $2374.8 * * *$ & $11.7 * * *$ \\
\hline
\end{tabular}

$\overline{\mathrm{Ns}}, * * *$ Nonsignificant or significant at $P=0.001$, respectively.

Table 5. Contrast mean squares for leaf rating of cucumber leaves inoculated with Didymella bryoniae. Cultigens differing for resistance to $D$. bryoniae were tested in a greenhouse. Time of inoculation was at dawn or dusk. Plant size was cotyledon, first, or third true leaf stage. Wound status was wounded or not wounded before inoculation. Ratings were measured 14 days after inoculation and ranged from no symptoms (0) to complete necrosis (9) in $11 \%$ increments of necrotic area. The experiment had four replications and was performed twice.

\begin{tabular}{lcc}
\hline \hline Contrasts & df & Rating \\
\hline Dawn-inoculated, not wounded vs. dusk-inoculated, not wounded & 1 & $62.0^{* * *}$ \\
Dawn-inoculated, wounded vs. dusk-inoculated, wounded & 1 & $4.1^{\mathrm{N} \mathrm{s}}$ \\
Cotyledon, not wounded vs. leaf 1, not wounded & 1 & $57.3^{* * *}$ \\
Cotyledon, wounded vs. leaf 1, wounded & 1 & $6.2^{\mathrm{Ns}}$ \\
Leaf 1, not wounded vs. leaf 3, not wounded & 1 & $13.3^{*}$ \\
Leaf 1, wounded vs. leaf 3, wounded & 1 & $7.2^{\mathrm{Ns}}$ \\
\hline
\end{tabular}

"s*,***Nonsignificant or significant at $P=0.05$ or 0.001 , respectively. 
the first three true leaves $(P \leq 0.05$ to 0.001$)$ were significantly different for stomata density, stomata length, and hydathode count. Mean stomata density ranged from $307 / \mathrm{mm}^{2}$ for PI 164433 to $875 / \mathrm{mm}^{2}$ for 'Wisconsin SMR 18'. Stomata length ranged from $14.8 \mathrm{~mm}$ for NCSU M 17 to $24.7 \mathrm{~mm}$ for PI 205995. Hydathode counts ranged from $2.5 / \mathrm{cm}$ for PI 164433 to $6.4 / \mathrm{cm}$ for 'Slice'. For all cultigens tested, stomata length increased and hydathode counts decreased with increasing leaf age, and the greatest difference occurred between the second and third true leaves (Table 4). No trends were associated with leaf age for stomata density. On average, stomata occurred more frequently near the center of leaves $\left(699 / \mathrm{mm}^{2}\right)$ compared with leaf margins $\left(560 / \mathrm{mm}^{2}\right)$. Stomata length at the center of the leaf was not significantly different from that found near the leaf margin. Stomata were more frequent $\left(750 / \mathrm{mm}^{2}\right)$ and longer $(19.9 \mathrm{~mm})$ on the abaxial leaf surface compared with the adaxial surface (508 per $\mathrm{mm}^{2}$ and $\left.18.4 \mathrm{~mm}\right)$.

Pearson product-moment and Spearman rank correlations were calculated between the field leaf rating data of Wehner and St. Amand (1993) and all three variables measured in this test to investigate possible relationships between field resistance and stomata or hydathode characteristics. Stomata density and hydathode count were not correlated with field resistance. When averaged over all three true leaves, stomata length was not correlated with field ratings; however, for the oldest leaf (leaf 1), stomata length was highly correlated $(r=0.89, P \leq 0.05)$ with field leaf ratings and field ranking $(r=0.83, P \leq 0.05)$.

Greenhouse methods. Plants inoculated at dawn were significantly $(P \leq 0.01)$ more susceptible $(5.1)$ than those inoculated at dusk (4.6). Droplets of guttation exudates were abundant at the leaf margins of plants inoculated at dawn, and the leaf blades were covered with a thin film of moisture due to guttation or condensation. Leaves inoculated at dusk appeared to be completely dry. Plant size and wound status at inoculation were both highly significant effects $(P \leq 0.001)$. Plants at the cotyledon stage were significantly less susceptible (4.4) than those at the first (5.0) or third (5.3) true leaf stage. The youngest leaves on seedlings with three true leaves were usually the least susceptible. Plants were more susceptible if wounded (6.2) before inoculation compared with nonwounded plants (3.4). Wound status interacted with time of inoculation and plant size $(P \leq 0.01)$. Single degree of freedom contrasts (Table 5) indicate that, for nonwounded plants, dawninoculated plants were more susceptible (4.1) than dusk-inoculated plants (3.1), and plants at the cotyledon stage (2.6) were less susceptible than those at the first true leaf stage (3 .7). Plants at the first true leaf stage (3.7) were less susceptible than those at the third true leaf stage (4.3) (Table 5). Wounded plants, however, showed no significant difference for inoculation time or plant size (Table 5).

Standard deviations were used as a measure of the range of ratings for each treatment and for each treatment combination. The actual range was not used because in many cases the range was the same. Also, individual outliers can affect the range greatly, but only minimally affect the standard deviation. Wound status was the factor with the largest effect on the range of plant ratings. Wounding decreased the standard deviation for ratings from 2.38 for nonwounded plants to 2.04. Plant size and time of inoculation, as main effects, had little effect on the range of plant ratings. Interactions between the three factors, however, had large effects on the range of plant ratings. The treatment combination of dawninoculated, nonwounded plants at the first true leaf stage had the largest standard deviation (2.72). Dawn-inoculated, nonwounded plants at the third true leaf stage had the second largest standard deviation (2.47), and dusk-inoculated, nonwounded plants at the cotyledon stage had the smallest standard deviation (1.59).

Correlations between field and greenhouse ratings were calculated for each treatment combination. Correlations were usually low and nonsignificant, except for dawn-inoculated, nonwounded plants at the third true leaf stage. Correlations with field ratings for that treatment combination were high $(r=0.88, P \leq 0.05$ in Expt. 1 and $r=0.96, P \leq 0.01$ in Expt. 2). Rank correlations were also high for that treatment combination $(r=0.83, P \leq 0.05$ in Expt. 1 and $r$ $=0.89, P \leq 0.05$ in Expt. 2).

Field methods. Single degree of freedom contrasts indicate that summer-grown cucumbers were significantly $(P \leq 0.001)$ more susceptible than spring-grown plants for leaf, stem, and index ratings (Table 6). Plants grown at Castle Hayne, were more susceptible $(P \leq 0.001)$ than those grown at Clayton for leaf (6.7 vs. $4.5)$, stem (4.9 vs. 3.3), and index (5.8 vs. 3.9) ratings. Irrigation treatments did not affect ratings. Large plants were significantly more susceptible than small plants for all three variables. Inoculating plants at dawn or wounding plants prior to inoculation, increased ratings for leaves and the index, but not for stems. Plant size interacted with wounding, but larger plants were more susceptible, regardless of wound status. The cultivar 'Slice' was the most resistant and 'Straight 8' was the most susceptible cultivar for all three variables. Several factors had significant interactions with cultivars (data not shown), but none caused a change in the rank of cultivars.

\section{Discussion}

Detached leaf tests and greenhouse tests both indicated that young leaves were less susceptible to D. bryoniae than were old leaves, at least for seedlings up to the fourth true leaf stage. The greatest differences in disease ratings occurred between the youngest leaves. Our results conflict with those of Van Steekelenburg (1985), who reported that wounding was necessary for infection of the second and third true leaf. Van Steekelenburg (1985) did not add sucrose or casein hydrolysate to the leaf surface or to the inoculum before inoculation. Work by Svedelius and Unestam (1978) demonstrated the importance of phylloplane nutrients in the infection process of $D$. bryoniae on cucumber. Our greenhouse tests did include supplemental nutrients in the inoculum and that is likely the reason for the different results. As in detached-leaf tests and greenhouse tests, younger tissue was less susceptible than older tissue in field tests. Leaves and stems both were more susceptible on plants larger than the vine tip over stage compared with plants having fewer than eight true leaves.

In greenhouse tests, seedlings at the cotyledon stage were less susceptible than seedlings with true leaves. Also, seedlings at the cotyledon stage had a smaller range of ratings and were more likely than larger seedlings to escape infection. These observations confirm the assertion of Wyszogrodzka et al. ( 1986) that resistance tests using cotyledon stage seedlings are unreliable.

Detached-leaf tests were convenient to conduct and usually had smaller coefficients of variation than greenhouse tests but were not correlated with field results. Inoculum used in the detached-leaf tests did not have supplemental nutrients, as in the greenhouse screening, due to the stimulating effect that nutrients had on the growth of secondary organisms. Rinsing detached leaves before inoculation to reduce the number of surface organisms probably removed guttation exudates from leaves and maybe responsible for the lack of correlation between field and detached-leaf ratings. Testing nonrinsed detached leaves was unreliable, due to the growth of numerous secondary organisms. 
Table 6. Mean rating of main effects for three cucumber cultivars tested in five environments, with supplemental irrigation zero, one, or three times a week, for plants smaller or larger than the vine tip over stage, with or without wounding, and inoculated at dawn or dusk with Didymella bryoniae. Leaves and stems were rated 10 to 14 days after inoculation and whole plot ratings ranged from no symptoms (0) to complete necrosis (9) in $11 \%$ increments of necrotic area. Index rating is the average of leaf and stem ratings for each plot.

\begin{tabular}{|c|c|c|c|c|}
\hline Factor & Level & Leaf & Stem & Index \\
\hline \multirow[t]{2}{*}{ Environment } & Spring & $4.0 \mathrm{~b}^{\mathrm{z}}$ & $2.7 \mathrm{~b}$ & $3.4 \mathrm{~b}$ \\
\hline & Summer & $6.1 \mathrm{a}$ & $4.4 \mathrm{a}$ & $5.2 \mathrm{a}$ \\
\hline \multirow{3}{*}{ Irrigations } & Zero times & $5.2 \mathrm{a}$ & $3.7 \mathrm{a}$ & $4.5 \mathrm{a}$ \\
\hline & One time & $5.1 \mathrm{a}$ & $3.6 \mathrm{a}$ & $4.4 \mathrm{a}$ \\
\hline & Three times & $5.3 \mathrm{a}$ & $3.7 \mathrm{a}$ & $4.5 \mathrm{a}$ \\
\hline \multirow[t]{2}{*}{ Plant size } & Large & $5.9 \mathrm{a}$ & $4.3 \mathrm{a}$ & $5.1 \mathrm{a}$ \\
\hline & Small & $4.5 \mathrm{~b}$ & $3.2 \mathrm{~b}$ & $3.8 \mathrm{~b}$ \\
\hline \multirow{2}{*}{ Wound status } & Wounded & $5.7 \mathrm{~b}$ & $3.8 \mathrm{a}$ & $4.7 \mathrm{a}$ \\
\hline & Nonwounded & $4.7 \mathrm{~b}$ & $3.6 \mathrm{a}$ & $4.2 \mathrm{~b}$ \\
\hline \multirow[t]{2}{*}{ Inoculation } & Dawn & $5.5 \mathrm{a}$ & $3.7 \mathrm{a}$ & $4.6 \mathrm{a}$ \\
\hline & Dusk & $4.9 \mathrm{~b}$ & $3.6 \mathrm{a}$ & $4.3 \mathrm{~b}$ \\
\hline \multirow[t]{3}{*}{ Cultivar } & Straight 8 & $6.4 \mathrm{a}$ & $4.0 \mathrm{a}$ & $5.2 \mathrm{a}$ \\
\hline & Dasher II & $5.3 \mathrm{~b}$ & $3.9 \mathrm{a}$ & $4.6 \mathrm{~b}$ \\
\hline & Slice & $3.9 \mathrm{c}$ & $3.3 \mathrm{c}$ & $3.6 \mathrm{C}$ \\
\hline
\end{tabular}

${ }^{\overline{ }}$ Within main effects and rating variable, means followed by the same letter are not significantly different at $P=0.05$ probability level based on LSD tests (or contrasts for environments),

Infrequent entrance of $D$. bryoniae through the stomata of watermelon rind has been noted by Schenck (1962). However, it was assumed by Svedelius and Unestam (1978) that stomatal entrance was not an important mode of entry for D. bryorriae. In tlis study, stomata density and hydathode counts were not correlated with susceptibility, but stomata length on older leaves was highly correlated with susceptibility. Also, stomata length increased with leaf age and older leaves were more susceptible. Our results indicate that stomata entry may be an important mode of entry for D. bryoniae on cucumber leaves and that further work on the mode of entry should proceed.

Guttation in seedlings was reduced by kinetin treatments and increased by 2,4-D treatments. Kinetin acts within $3 \mathrm{~h}$ directly on stomata to increase stomatal aperture and increase transpiration (Incoll and Jewer, 1987), and 2,4-D induces stomatal closure and reduces transpiration (Davies and Mansfield, 1987). In this study, susceptibility increased as guttation increased and actively guttating plants were more susceptible than nonguttating plants, indicating that guttation is important in the disease process. Guttation and turgidity greatly increased in a mutant tomato (Lycopemicon esculentum Mill.) plant, when normal stomata closure was restored using exogenously applied abscisic acid (Imber and Tal, 1970). It is likely that guttation was increased in this study due to higher plant turgor induced by closed stomata for plants treated with 2,4-D. The opposite was true for plants treated with kinetin: guttation and susceptibility decreased presumably due to open stomata. Although applying 2,4-D to seedlings increased guttation and susceptibility, its effect on plants is to close stomata. Therefore, high levels of infection are possible with apparently closed stomata on nonwounded plants if guttation is occurring. Also, low levels of infection are possible with apparently open stomata on nonwounded plants if guttation does not occur. It appears that phylloplane moisture and nutrition are more important in the infection process of $D$. bryoniae on cucumber leaves than is stomatal opening. Svedelius and Unestam (1978) concluded that nutrients on leaf surfaces were more important than wound openings for infection of cucumber by $D$. bryoniae. Guttation is increased by soil fertilization (Ivanoff, 1963; Blakeman, 1971) and the nutrient content of guttation exudates are affected by soil fertility (Curtis, 1944). Van Steekelenburg (1982) found that external fruit susceptibility increased with increasing nitrogen fertilization of cucumbers, and Van Steekelenburg and Welles (1988) reported that $\mathrm{Ca}$ fertilization levels influence susceptibility.

Increasing leaf moisture in field tests by increasing the frequency of irrigation did not increase disease ratings as expected. It is possible that irrigation treatments were not frequent enough to achieve constant free water. Several workers have indicated that free water is required for infection (Olsen and Stanghellini, 198 1; Van Steekelenburg, 1983; and Van Steekelenburg, 1985). Dawn inoculation did increase leaf susceptibility compared with dusk inoculation. The increase was likely due to the free water and nutrients provided by guttation.

Wyszogrodzka et al. (1986) reported that the correlation between Wisconsin and Florida field tests for cultigen rank was low to moderate $(r=0.43)$. St. Amand and Wehner (1993) reported moderate to high ( $r=0.48$ to 0.93 ) correlations between years for field tested cucumbers. Compared to field tests, a greenhouse test would facilitate breeding efforts to locate or improve field resistance if it were highly correlated with field tests. In this study, a useful greenhouse screening method, which is highly correlated with field ratings and provides a wide range of ratings, was developed. The best results were obtained by inoculation of seedlings at the third true leaf stage with $1 \times 10^{6}$ spores $/ \mathrm{ml}$ of inoculum, using inoculum amended with sucrose and casein hydrolysate, applying inoculum to guttating plants at dawn, applying inoculum as a fine mist with minimal guttation exudate runoff, incubating inoculated plants in the dark at $25 \mathrm{C}$ and $95 \%$ to $100 \%$ for $48 \mathrm{~h}$, acclimating dark incubated plants to greenhouse conditions for $24 \mathrm{~h}$, and rating plants for foliar necrosis 10 to 14 days after inoculation. Our greenhouse screening test should be useful for progeny testing of cucumber germplasm.

A better understanding of the relationship between guttation and infection and the possible and preferred modes of entry of $D$. bryoniae on cucumber leaves and stems will likely lead to improved screening methods and provide a basis for understanding cucumber resistance to D. bryoniae. 


\section{Literature Cited}

Blakeman, J.P. 1971. The chemical environment of the leaf surface in relation to growth of pathogenic fungi, p. 255-268. In: T.F. Preece and C.H. Dickinson (eds.). Ecology of leaf surface micro-organisms. Academic Press, London.

Campbell, C.L. and L.V. Madden. 1990. Introduction to plant disease epidemiology. Wiley, New York.

Chiu, W.F. 1948. Pathogenicity of Mycosphaerella citrullina. Phytopathology 38:5. (Abstr.)

Chiu, W.F. and J.C. Walker. 1949. Physiology and pathogenicity of cucurbit black-rot fungus. J. Agr. Res. 78:589-615.

Curren, T. 1969. Pectic and cellulolytic enzymes produced by Mycosphaerella citrullina and their relation to black rot of squash. Can. J. Bet. 47:791-794.

Curtis, L.C. 1944. Deleterious effects of guttated fluids on foliage. Amer. J. Bet. 30:778-781 .

Davies, W.J. and T.A. Mamsfield. 1987. Auxins and stomata, p. 293-309.

In: E. Zeiger, G.D. Farquhar, and I.R. Cowan. (eds.). Stomatal function. Stanford Univ. Press, Stanford, Calif.

Deadman, M.L. and B.M. Cooke. 1986. A comparison of detached leaf, greenhouse, and field experiments for screening barley cultivars to Drechslera teres. Irr. J. Agr. Res. 25:63-70.

de Neergaard, E. 1989. Histological investigation of flower parts of cucumber infected by Didymella bryoniae. Can. J. Plant Pathol. 11:2838 .

Fernandez, G.C.J. 1992. Residual analysis and data transformations: important tools in statistical analysis. HortScience 27:297-300.

Hordijk, C.V. and P.G. Goosen. 1962. Aantasting van komkommer door Mycosphaerella melonis. Tidjdschrift over Plantenzickten. 68:149. (Abstr.)

Hughes, G.R., C.W. Averre, and K.A. Sorensen. 1983. Growing pickling cucumbers in North Carolina. North Carolina Agr. Ext. Serv. AG-315.

Incoll, L.D. and P.C. Jewer. 1987. Cytokinins and stomata, p. 281-292. In

E. Zeiger, G.D. Farquhar, and I.R. Cowan. (eds.). Stomatal function. Stanford Univ. Press, Stanford, Calif.

Imber, D. and M. Tal. 1970. Phenotypic reversion of Flacca, a wilty mutant of tomato, by abscisic acid. Science 169:592-593.

Ivanoff, S.S. 1963. Guttation injuries of plants. Bet. Rev. 29:202-229.

Lee, D., S.B. Mathur, and P. Neergaard. 1984. Detection and location of seed-borne inoculum of Didymella bryoniae and its transmission in seedlings of cucumber and pumpkin. Phytopathol. Z. 109:301-308.

Little, T.M. 1985. Analysis of percentage and rating scale data. HortScience 20:642-644.

Olsen, M.W. and M.E. Stanghellini. 1981. Mycosphaerella melonis on greenhouse cucumber. Plant Dis. 65:157-159.

Prasad, K. and J.D. Norton. 1967. Inheritance of resistance to Mycosphaerella citrallina in muskmelon. J. Amer. Soc. Hort. Sci. 91:396-400.

Randhawa, P.S. and E.L. Civerolo. 1985. A detached-leaf bioassay for Xanthomonas campestris pv. pruni. Phytopathology 75:1060-1063.
SAS Institute. 1988. SAS/STAT user's guide. release 6.03. SAS Inst., Cary, N.C.

Schenck, N.C. 1962. Mycosphaerella fruit rot of watermelon. Phytopathology 52:635-638.

St. Amand, P.C. and T.C. Wehner. 1993. Correlations between years for foliar gummy stem blight disease ratings on field grown cucumbers, Cucurbit Genet. Coop. Rpt. 16:1-2.

Svedelius, G. 1990. Effects of environmental factors and leaf age on growth and infectivity of Didymella bryoniae. Mycol. Res. 94:885-889.

Svedelius, G. and T. Unestam. 1978. Experimental factors favoring infection of attached cucumber leaves by Didymella bRyoniae. Trans. Br. Mycol. Soc. 71:89-97.

Tedford, E. C., T.L. Miller, and M.T. Nielsen. 1990. A detached-leaf technique for detecting resistance to Phytophthora parasitic var. nicotianae in tobacco. Plant Dis. 74:313-3 16.

Thompson, D.C. and S.F. Jenkins. 1985. Pictorial assessment key to determine fungicide concentrations that control anthracnose development on cucumber cultivars with varying resistance level. Plant Dis. 69:833-836.

Van Der Meer, Q. P., J.L. Van Bennekom, and A.C. Van Der Giessen, 1978. Gummy stem blight resistance of cucumbers (Cucumis sativus L.). Euphytica 27:861-864.

Van Steekelenburg, N.A.M. 1981. Comparison of inoculation methods with Didymella Bryoniae on Cucumis sativus. Euphytica 30:515-520.

Van Steekelenburg, N.A.M. 1982. Factors influencing external fruit rot of cucumber caused by Didymella bryoniae. Neth. J. Plant Pathol. 88:4756.

Van Steekelenburg, N.A.M. 1983. Epidemiological aspects of Didymella bryoniae, the cause of stem and fruit rot of cucumber. Neth. J. Plant Pathol. 89:75-86.

Van Steekelenburg, N.A.M. 1985. Influence of humidity on incidence of Didymella bryoniae on cucumber leaves and growing tips under controlled environmental conditions. Neth. J. Plant Pathol. 91:277-283.

Van Steekelenburg, N.A.M. and G.W.H. Welles. 1988. Influence of day/ night humidity and cation ratios and concentration in the nutrient solution on incidence of Didymella bryoniae in glasshouse cucumbers. Neth. J. Agr. Sci. 36:225-230.

Wehner, T.C. 1987. Genotype-environment interaction for cucumber yield in 23 North Carolina environments. Cucurbit Genet. Coop. Rpt. 10: $25-26$.

Wehner, T.C. and R. Horton. 1992. NCSU cucumber breeding report. Dept. of Hort. Sci., North Carolina State Univ.

Wehner, T.C. and P.C. St. Amand. 1993. Field tests for resistance to gummy stem blight of cucumber in North Carolina. HortScience 28:327329.

Wyszogrodzka, A.J., P.H. Williams, and C.E. Peterson. 1986. Search for resistance to gummy stem blight (Didymella bryoniae) in cucumber (Cucumis sativus L.). Euphytica 35:603-613.

Yarwood, C.E. 1946. Detached leaf culture. Bet. Rev. 12:1-56.

Yarwood, C.E. 1952. Guttation due to leaf pressure favours fungus infections Phytopathology 42:520. (Abstr.) 